\title{
BMJ Open Joint observation in NICU (JOIN): study protocol of a clinical randomised controlled trial examining an early intervention during preterm care
}

\author{
Juliane Schneider, ${ }^{\oplus 1}$ Ayala Borghini, ${ }^{2,3}$ Mathilde Morisod Harari, ${ }^{2}$ Noemie Faure, ${ }^{1}$ \\ Chloé Tenthorey, ${ }^{1}$ Aurélie Le Berre, ${ }^{1}$ Jean-François Tolsa, ${ }^{1}$ Antje Horsch, ${ }^{4,5}$ on \\ behalf of the JOIN Research Consortium
}

To cite: Schneider J, Borghini A, Morisod Harari M, et al. Joint observation in NICU (JOIN): study protocol of a clinical randomised controlled trial examining an early intervention during preterm care. BMJ Open 2019;9:e026484. doi:10.1136/ bmjopen-2018-026484

- Prepublication history for this paper is available online. To view these files, please visit the journal online (http://dx.doi org/10.1136/bmjopen-2018026484).

Received 4 September 2018 Revised 4 February 2019 Accepted 6 February 2019

Check for updates

(C) Author(s) (or their employer(s)) 2019. Re-use permitted under CC BY-NC. No commercial re-use. See rights and permissions. Published by BMJ.

For numbered affiliations see end of article.

Correspondence to Professor Antje Horsch; antje.horsch@chuv.ch

\section{ABSTRACT}

Introduction Preterm birth may generate significant distress among the parents, who often present with difficulties in appropriating their parental role. Parental stress and low perceived parental self-efficacy may interfere with the infant's socioemotional and cognitive development, particularly through disrupted parent-infant interactions. Perceived parental self-efficacy represents the belief of efficacy in caring for one's own infant and successful incarnation of the parental role, as well as the perception of one's own abilities to complete a specified task. Interventions to support parental role, as well as infant development, are needed, and parental self-efficacy represents a useful indicator to measure the effects of such early interventions. Methods and analysis This study protocol describes a randomised controlled trial that will test an early intervention in the neonatal intensive care unit (NICU) (JOIN: Joint Observation In Neonatology) carried out by an interdisciplinary staff team. Mothers of preterm neonates born between 28 and 32 6/7 weeks of gestational age are eligible for the study. The intervention consists of a videotaped observation by a clinical child psychologist or child psychiatrist and a study nurse of a period of care delivered to the neonate by the mother and a NICU nurse. The care procedure is followed by an interactive video guidance intended to demonstrate the neonate's abilities and resources to his parents. The primary outcome will be the difference in the perceived maternal self-efficacy between the intervention and control groups assessed by self-report questionnaires. Secondary outcomes will be maternal mental health, the perception of the parent- infant relationship, maternal responsiveness and the neurodevelopment of the infant at 6 months corrected age.

Ethics and dissemination Ethical approval was granted by the Human Research Ethics Committee of the Canton de Vaud (study number 496/12). Results from this study will be disseminated at national and international conferences, and in peer-reviewed journals.

Trial registration number NCT02736136, Pre-results.

\section{INTRODUCTION}

Advances in neonatal care

Improvement of prenatal and postnatal care over the past decades has led to increased
Strengths and limitations of this study

- The study will test the effects of an early intervention carried out by an interdisciplinary partnership between neonatal intensive care unit nurses and clinical child psychologists/child psychiatrists.

- Among other objectives, the intervention aims at increasing perceived parental self-efficacy in mothers of very preterm infants.

- The intervention draws on theories of neonatal and infant development, as well as interactive video guidance.

- Methodological rigour, including concealment of random allocation and prospective trial registration and publication, limits risk of bias.

- Unblinded participants and clinicians, as well as contamination due to improvement of usual care by healthcare providers, may increase the risk of bias.

survival of very preterm neonates born less than 32 weeks' gestation. ${ }^{1}$ Among others, protective measures to promote health and subsequent neurodevelopment have been developed, including optimisation of nutritional support, better characterisation of neonatal stress and improved pain management. In the same perspective, developmental care was introduced in the neonatal intensive care units (NICU) since the 1990s with the intention of minimising the adverse consequences of prematurity on the developing brain. During a critical period of development, the preterm brain is highly vulnerable to injury, represented by cerebral haemorrhage and insult to the white matter. Additionally, beyond the injury, preterm neonates are prone to alteration of brain maturation with disruption of normal developmental trajectory of both grey and white matters. $^{2-4}$ 


\section{DEVELOPMENTAL CARE}

Over the last two decades, a growing body of research focused on the impact of excessive stimuli such as sound, light, touch or pain on the preterm neonate, hypothesising that an unfavourable and stressful environment may add to the adverse effects of neonatal morbidity. ${ }^{5}$ These concerns led progressively to the introduction of developmental care, which consists of individualised strategies mainly based on the neonate's skills and/or difficulties, ${ }^{6}$ and supporting the neonate's regulation and development. The first aim of the developmental care is to limit exposure to deleterious environmental stimulations. Management of sensorial dystimulation, as well as of pain and stress during invasive care procedures, represents a central target of developmental care. ${ }^{78}$ The second main objective focuses on the child's well-being through the adaptation of the sensorial environment in order to provide more physiological external stimuli (tactile, auditory, visual, vestibular), that will help to promote behaviours and postures fostering comfort and regulation. The third objective of the developmental care aims to support parents in their role and to strengthen the relationship they are developing with their child. ${ }^{7910}$ Although studies have found contradictory results, ${ }^{11-13}$ some evidence shows a positive impact of developmental care on short-term and long-term neonatal and neurodevelopmental outcomes. ${ }^{14-19}$ Taken together, the different aspects of developmental care aim to build support around the neonate and the family, leading to the development of 'family-centred care', with specific recommendations for its implementation in the NICU. ${ }^{20-22}$

\section{Impact of prematurity on parents' well-being}

Preterm birth and caring for a preterm infant may be distressing for parents, who often feel vulnerable and incompetent in the high-tech NICU environment. ${ }^{23-25}$ Parents may present with difficulties in understanding and capturing subtle cues from their infant. ${ }^{26}$ Parents show important signs of stress, ${ }^{27}$ and require more support during the first year after the preterm birth compared with parents of term infants. ${ }^{28}$ They may also experience mental health symptoms, including post-traumatic stress disorder (PTSD) ${ }^{29-35}$ anxiety and depression. ${ }^{25} 36$

Although the hospitalisation of a preterm neonate may affect both parents equally, ${ }^{36}$ most of the studies examining parental emotional distress so far focused on mothers' experience and needs. ${ }^{24} 3738$ After birth, the mother normally initiates specific behaviours towards her newborn, aimed at supporting the neonate who experiences high levels of stress during hospitalisation in the NICU, ${ }^{39}$ and at fostering the infant's socioemotional development. ${ }^{40} 41$ However, mothers of preterm infants may present difficulties in developing these protective behaviours. ${ }^{42}$ Thus, parental stress may interfere with the infant's socioemotional and cognitive development, and is associated with more difficulties in building positive parent-infant relationships due to disrupted interactions. ${ }^{4044}$ However, a recent meta-analysis showed that mothers of preterm children were not less sensitive or responsive toward their children than mothers of fullterm children. ${ }^{45}$

\section{Perceived parental self-efficacy}

Perceived parental self-efficacy is defined as 'beliefs or judgements a parent holds of their capabilities to organise and execute a set of tasks related to parenting a child'. ${ }^{46}$ Self-efficacy includes two separate notions: first, the belief of efficacy in caring for one's own child across several varied domains of functioning and successful incarnation of the parental role (general self-efficacy), ${ }^{47-49}$ and second, the perception of one's own abilities to complete a specified task within a specific domain (specific self-efficacy) ${ }^{50}$ The present study will focus on the specific self-efficacy, which appears to drive actions and predicts parents' behaviours. ${ }^{4851}$

As demonstrated in previous studies, perceived parental self-efficacy appears to mediate the relationship between psychosocial risk factors and maternal competences. ${ }^{52} 53$ Thus, a perception of low self-efficacy is associated with parental depression, ${ }^{52}{ }^{54-57}$ high levels of parenting stress, ${ }^{58} 59$ low family support,${ }^{60}$ poor infant health $^{5961}$ and demanding infant temperament. ${ }^{62}{ }^{63}$ In contrast, a perception of high self-efficacy is associated with sensitive and receptive parental behaviour, and is related to improved infant socioemotional development. ${ }^{5664}$

Parents of preterm neonates face a complex challenge. While they might be responsive to their infant cues, preterm neonates might not be capable of engaging in sustained and responsive interaction, as they tend to be less attentive and reactive due to immaturity, and to show more negative behaviours and emotions, as well as less rewarding interactions than their term-born peers. ${ }^{56} 65-67$ In parallel, mothers of preterm neonates, who are at risk of experiencing depression, anxiety or post-traumatic disorder, ${ }^{25}{ }^{35}$ may not be able to interact as adequately with their child, and could be less sensitive than mothers without mental health symptoms. Mothers of preterm infants may be at a higher risk of decreased maternal confidence, ${ }^{68}$ although the limited evidence available so far is mixed. ${ }^{5769}$ The quality of care provided by parents is strongly influenced by the maternal perception of self-efficacy, and interventions promoting this may therefore help to increase parenting quality. ${ }^{49} 70$

To date, only few early interventions have focused on enhancing perceived parental self-efficacy. The interventions that are currently available in the early neonatal period mainly aim to decrease parental trauma and stress-related symptoms, and to improve parental responsiveness within the parent- infant interaction. ${ }^{10} 23$ 71-73 Thus, a recent meta-analysis identified only two interventions intended to increase perceived maternal self-efficacy. ${ }^{74-76}$ These two interventions concentrated on different techniques of parenting education, and one of the two demonstrated improved cognitive child development at 4 months of age. ${ }^{76}$ The present study focuses on 
the joint observation, which is an interdisciplinary intervention performed in the NICU soon after birth. The main aim of the study is to examine whether this early intervention increases perceived parental self-efficacy.

\section{Joint observation}

The joint observation (JOIN: Joint Observation In Neonatology ${ }^{77}$ ) was developed in line with the three objectives of the developmental care model. This early intervention programme in the NICU is carried out by an interdisciplinary partnership of professionals, thereafter called observers, including NICU nurses, paediatricians, clinical child psychologists or child psychiatrists. They all received a 20-hour training, delivered by the same experienced clinical child psychologist $(\mathrm{AB})$ for consistency, and participate in regular supervision sessions during the study period.

The intervention combines elements issued from four distinct theories of neonatal and infant development. First, the evaluation of neonatal behaviour developed by Brazelton and Nugent ${ }^{78}$ underlines the importance of parents detecting the neonate's competences and fragilities, and interpreting stress cues to adjust to the infant's regulation needs. Second, the synactive model of $\mathrm{Als}^{79}$ proposes a programme of individualised care avoiding overstimulation in the NICU and supporting the neonate's self-regulation and competences. Third, the sensorimotor approach elaborated by Bullinger ${ }^{80}$ consists mainly of the assessment of sensory dystimulations provided to the neonate, and the management of subsequent tonico-postural disturbances observed during the NICU stay with the long-term perspective of optimising the infant's development. This approach builds a framework to adjust the care procedures to the neonate's capacity to treat multisensory information, and to reach a sensoritonic balance that allows and supports interactive behaviours. Fourth, the interactive guidance is a model based on the observation and analysis of parent-infant interactions through the therapeutic use of video feedback. ${ }^{81-83}$ This approach aims to allow parents to become aware of their competences and resources, as well as the skills and needs of their infant. Video feedback has recently been studied as an intervention in the NICU. ${ }^{84}{ }^{85}$ The authors postulated that the interactive guidance through video feedback reduces the negative impact of preterm birth on the parent-infant relationship, and the behavioural withdrawal of the parent. The results of this previous work have revealed increased parental sensitivity and positive effects on the developing relationship. ${ }^{84}$ A randomised clinical study implementing video feedback not only during the NICU stay but also during the first year of life specifically demonstrated positive effects on parents of preterm infants with a lowering of mothers' post-traumatic stress symptoms and enhancement in maternal sensitivity and quality of mother-infant interactions. ${ }^{86}$

In order to address the main objective, the present intervention is focusing on following areas: (1) The neonate's adaptive capacity and competences are highlighted, as well as interactive signals, in order to promote parents' emotional involvement, awareness of the infant's perspective, resources and needs. For instance, the neonate's interactive initiatives, as well as the responses to parental touch and/or voice, such as eye opening or head turning, will be highlighted. (2) To reinforce parental responsiveness, the parent's behaviours that are supporting the neonate's signals are pointed out during the video extracts, highlighting the parental relational competences frequently unidentified by the parents themselves. For example, positive emotional interactions between the mother and her neonate will be emphasised, such as adapting the voice and facial expression in order to support the neonate's alertness. (3) With the aim of developing individualised care, measures can be suggested acknowledging the specificities of each neonate (sensorial irritability, tonico-postural disturbances or withdrawal for instance), and adjusting the care to reinforce the neonate's own capacity of autoregulation and to support sensoritonic balance development in a long-term perspective. For instance, the parent's gestures of support according to the baby's tonico-postural needs will be identified, such as supporting the baby's neck or pelvis during the interaction or adjusting the rhythm to help the neonate developing autoregulation competencies.

The joint observation pragmatically consists of two phases. First, a video-recorded period of routine care for the preterm neonate (such as a nappy change) is carried out by both the parent (mostly the mother) and a NICU nurse for a duration of approximately $30 \mathrm{~min}$.

There is no intervention by the observers during the videotaping. Second, before gathering with the mother, several short extracts of the period of care are carefully selected by the observers in order to reach the objectives of the intervention. During the discussion and for illustration purpose, the observers will play back 4-6 short extracts of 10-30s each to the parents, showing short specific moments of interactive behaviours that usually escape awareness. This video feedback, which lasts about $60 \mathrm{~min}$, is conducted in order to point out the quality of the relational and emotional parent-infant interactions, and highlights moments of attunement, adjustment, synchrony, reciprocity and mutuality.

\section{Aims of the present study}

The objectives of the present study are to measure the effects of the joint observation as an early intervention performed in the NICU on outcomes relative to parental perception and mental health, as well as to indices of the parent-infant relationship quality and of child development. The primary outcome measure will be the perceived maternal self-efficacy. Secondary objectives will be to measure the impact of this intervention on maternal mental health (including perceived stress, post-traumatic stress, anxiety, depression), on maternal perception of the parent-infant relationship, on maternal responsiveness and on the neurodevelopment of the infant at 6 months 
corrected age (CA). In addition, acceptability of the intervention and maternal satisfaction will be assessed.

\section{METHODS AND ANALYSIS}

\section{Study design}

We will conduct a monocentric randomised controlled trial testing an intervention compared with treatment-asusual, in the level III NICU of a Swiss University Hospital.

\section{Study population, recruitment, group allocation and blinding}

All mothers of preterm neonates born between 28 and $326 / 7$ weeks of gestational age (GA), admitted to the NICU and aged less than 8 weeks of life are eligible to participate. Exclusion criteria were set for ethical considerations and in order to avoid approaching mothers needing acute treatment, and include the following: maternal age $<18$ years; established intellectual disability or psychotic illness; insufficient French-speaking level to complete questionnaires due to impossibility to obtain valid translations to multiple languages for financial reasons; and cardiorespiratory instability of the preterm neonate (severe brady-apnoea syndrome, oxygen requirement $>30 \%$ ) to ensure survival during the study period. Regarding twins or triplets, only the first-born neonate or the one being more stable will be included in the study.

Recruitment will be performed by the study nurses, who approach the eligible mothers once their infants are stable enough, that is, after the critical period of the first week of life when cardiorespiratory stability is established, usually on non-invasive ventilation and with oxygen requirement $<30 \%$, which would also permit more active participation of the parents in the neonate's care. The allocation ratio of randomisation is $1: 1$, using a computer-generated list of random blocks (https://www. sealedenvelope.com/simple-randomiser). The allocation sequence will be concealed from the principal investigator in sequentially numbered, opaque, sealed envelopes. Envelopes will be opened only after the enrolled participants gave signed consent and completed all baseline assessments. The principal investigator and the statistician will be blind to group allocation. All participant data will be coded to ensure confidentiality.

\section{Control group}

Participants in the control group will receive treatmentas-usual. They will be asked to complete questionnaires at the same time points as the participants in the intervention group: at recruitment, at 1 month after enrolment and at 6 months of their infant's CA. At 6 months CA, a neurodevelopmental assessment of the infant and a 10 min filmed mother- infant interaction will take place.

\section{Intervention group}

Mothers assigned to the intervention group will be asked to complete self-report questionnaires at the three time points described above. The intervention in the form of the joint observation will be planned after enrolment depending on the infant's clinical state and stability. The intervention is twofold: first, the observers are jointly observing a period of care administered to the neonate jointly by her mother and a NICU nurse. The care procedure is video-taped and an observation grid $^{87}$ is completed by the observers. Second, the mother and the NICU nurse participate in a video feedback session with the two observers. The discussion is based on the principles of interactive guidance, ${ }^{84}$ as described above. At the end of the intervention, the mother will also be asked to complete a questionnaire regarding her satisfaction with the intervention.

At 6 months CA, a neurodevelopmental assessment of the infant and a 10 min filmed mother-infant interaction will be carried out.

\section{Primary outcome}

The primary outcome is the difference in perceived maternal self-efficacy between the control and intervention groups measured with the Perceived Maternal Parenting Self-Efficacy questionnaire 1 month after study enrolment.

\section{Secondary outcomes}

Maternal outcomes

Using validated self-reported questionnaires described below, various aspects of maternal well-being will be compared between the two groups at baseline and at the 1-month and 6-month follow-up, including symptoms of PTSD (Posttraumatic Diagnostic Scale), parental stress (Parental Stressor Scale: Neonatal Intensive Care Unit and Parenting Stress Index-Short form), anxiety (Hospital Anxiety and Depression Scale) and depression (Edinburgh Postnatal Depression Scale). Other measures will include maternal perception of the parent-infant relationship (Mother-to-Infant Bonding Scale) and of her infant's temperament (Infant Behaviour QuestionnaireRevised), perceived social support (Modified Medical Outcomes Study Social Support Survey) and maternal sensitivity or responsiveness (Emotional Availability Scales and Care Index). In addition, acceptability and maternal satisfaction of the intervention will be assessed in the intervention group.

\section{Neonatal outcomes}

The neurodevelopmental outcome of the preterm neonates will be measured at 6 months CA (Bayley Scales of Infant Development, third edition [BSID-III]).

\section{Data collection and visits}

After enrolment, mothers will be asked to complete several questionnaires described below, and again 1 month after study enrolment and at 6 months CA. Infants will return at 6 months CA to the neonatal follow-up clinic for the neurodevelopmental assessment and the $10 \mathrm{~min}$ filmed mother-infant interaction. The study measures and timings are summarised in table 1 and figure 1. 
Table 1 The measures at the three different time points

\section{MEASURES}

\section{Self-report questionnaires}

Perceived Maternal Parenting Self-Efficacy

This questionnaire, including 20 items, which represent four subscales (care taking procedures, evoking behaviour(s), reading behaviours or signalling and situational beliefs), was specifically developed for mothers of preterm neonates, and has good psychometric properties. ${ }^{50}$ Responses to each item are recorded on a four-point

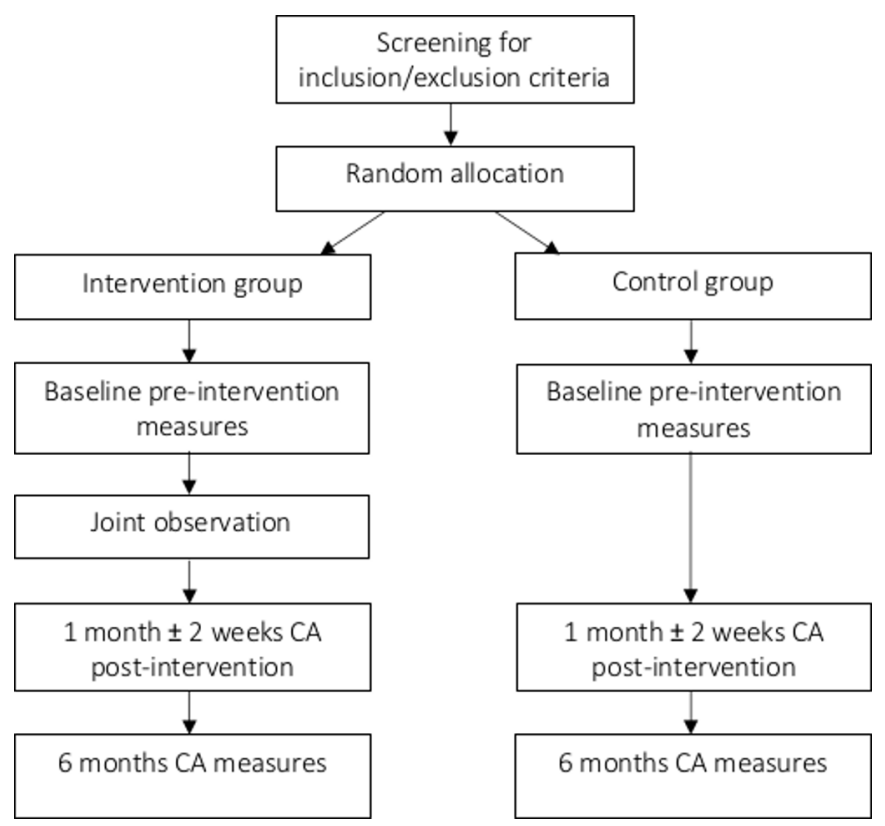

Figure 1 Flow chart of the study. CA, corrected age.
Likert scale (from 'strongly disagree', score 1, to 'strongly agree', score 4). To obtain a French version of the questionnaire, a translation and cultural adaptation were performed with the forward-backward method. ${ }^{88}$

\section{Posttraumatic Diagnosis Scale}

Maternal PTSD is measured using this 17-item scale based on Diagnostic and Statistical Manual of Mental Disorders, fourth edition, criteria. Mothers will rate frequency and severity of symptoms, such as re-experiencing, avoidance and hyperarousal, experienced over the last month and graded on a four-point Likert scale. The Posttraumatic Diagnosis Scale displays good psychometric properties, ${ }^{89}$ and a French version has been validated. ${ }^{90}$

\section{Parental Stressor Scale: neonatal intensive care unit}

This questionnaire was translated into French and assesses parental stress with 31 items focusing on their perception of stress factors during the NICU stay of their neonate and explores three domains: impact of the visual and auditory environment, behaviour and aspect of the neonate and parental role. ${ }^{91}$ Good psychometric properties have been reported. ${ }^{91}$

\section{Parenting Stress Index-short form}

This 36-item questionnaire is a shortened version of the Parental Stress Index, ${ }^{92}$ which measures the stress related to parenthood, and is intended for parents of children 0 to 3 years. The three subscales investigate parental distress, dysfunctional interactions between the parents and the child and child difficulties. Its validity has been 
demonstrated in studies of parents of preterm neonates. ${ }^{93}$ In this study, the validated French version will be used. ${ }^{94}$

Hospital Anxiety and Depression Scale

Anxiety and depression symptoms are assessed using the French version of the Hospital Anxiety and Depression Scale, which includes 14 items, and measures the severity of symptoms. ${ }^{95}$ This questionnaire has good psychometric properties. $^{96}$

\section{Edinburgh Postnatal Depression Scale}

Maternal depression symptoms will also be assessed with the Edinburgh Postnatal Depression Scale, which focuses on the symptoms experienced over the last 7 days. ${ }^{97}$ The French version displays good psychometric characteristics. $^{98}$

\section{Mother-to-Infant Bonding Scale}

In this questionnaire, the mother rates (from 0 to 5 ) eight adjectives describing her feelings toward her infant, which is indicative of mother-infant bonding ${ }^{99} 100$ and was translated into French with good psychometric properties. ${ }^{101}$

\section{Infant Behaviour Questionnaire-Revised Very Short Form}

Infant temperament is assessed through the French version of this questionnaire (total of 191 items). The parent reports on a seven-point Likert scale the frequency of his infant's behaviours during the previous 2 weeks. ${ }^{102}$ Good psychometric properties have been reported. ${ }^{102}$

\section{Modified Medical Outcomes Study Social Support Survey}

This validated self-reported evaluation consisting of eight items measuring different aspects of social support ${ }^{103}$ is based on the 19-item questionnaire assessing the dimensionality of four functional support scales (emotional/ informative, tangible, affectionate and positive social interaction). ${ }^{104} \mathrm{~A}$ French translation and cultural adaptation was performed using the forward-back method. ${ }^{88}$

\section{Questionnaire of satisfaction and acceptability of the intervention}

This questionnaire comprises a general question on maternal satisfaction with the intervention and six questions on its setting, value and usefulness, which will provide a qualitative evaluation. In addition, three questions focus on the acceptability of the intervention by the mothers.

\section{Demographic and perinatal characteristics}

Mothers will also report demographic information, including socioeconomic status, level of education ${ }^{105}$ and previous psychiatric disorder. Neonatal characteristics will be collected from the medical record on severity of morbidity (GA and weight at birth, Apgar score, complications-need for mechanical ventilation and respiratory morbidity, sepsis and cerebral lesions), as well as the Clinical Risk Index for Babies, ${ }^{106}$ which represents neonatal morbidity severity.

\section{Assessment of maternal sensitivity and responsiveness}

Maternal sensitivity will be assessed at 6 months CA by coding a session of free play between the mother and her infant with the Emotional Availability Scales. ${ }^{107}$ Six domains are evaluated, of which four relate to the mother's behaviour (sensitivity, structuration, intrusion and hostility toward the infant), and two to the infant's behaviour (reactivity to the mother and maternal involvement). Patterns of interaction and emotional availability can therefore be measured on separate scales. ${ }^{108}$

A second tool, the Care Index, ${ }^{109}$ will measure maternal sensitivity, by assessing the interactive behaviour within the mother-infant dyad according to seven scales (facial expressions, vocalisations, posture, expressed affection, turn-taking, control and activity). Three maternal (sensitive, controlling, passive) and four infant (cooperative, compulsive-compliant, demanding, passive) characteristic behaviours are coded on each scale.

\section{Neurodevelopmental assessment of the infant}

A standardised neurodevelopmental assessment will be conducted at 6 months CA by a developmental paediatrician, using the BSID-III, ${ }^{110}$ which entails three subscales (cognitive, language and motor) with a normative mean score of $100 \pm 15 \mathrm{SD}$.

\section{Sample size calculation}

Power calculation $\left(\mathrm{G}^{*} \text { Power }\right)^{111}$ based on published means and $\mathrm{SD}^{50} 55$ related to perceived parental self-efficacy in a sample of preterm $(\mathrm{M}=58.51, \mathrm{SD}=12.57)$ and of term-born $(\mathrm{M}=65.9, \mathrm{SD}=8.2)$ neonates showed that 68 participants would need to be recruited $(\alpha=0.05,1-\beta=0.80$, unilateral hypothesis). This is based on the assumption that parental self-efficacy in mothers of preterm babies in the intervention group who benefited from the intervention would be comparable to that in mothers of term babies. Therefore, it is planned that 80 mothers will be enrolled to anticipate possible participant withdrawal.

\section{Statistical analyses}

For the primary outcome regarding the difference in the perceived maternal self-efficacy between the intervention and control groups, linear regression analysis will be employed, with maternal self-efficacy at 1 month as the dependent variable and group as the explanatory variable, with adjustment for baseline maternal self-efficacy. For secondary analyses, linear mixed model regressions will be conducted, with maternal self-efficacy at 1 and 6 months as dependent variables and group, time and the interaction group $\mathrm{x}$ time as independent variables, adjusted for baseline maternal self-efficacy. The sample principle will be applied to all other secondary outcomes. We will include potential confounding variables, if necessary. These include maternal age, sex of the children and socioeconomic status where applicable. For confirmatory analyses, a Bonferroni correction for multiple analyses will be applied. For initial exploratory analyses, no such correction will be used. ${ }^{112}$ 
Differences between groups will be adjusted for the respective baseline values in case they differ using potential confounding variables, if necessary. These include maternal age, sex of children and socioeconomic status where applicable. Variables will be transformed if residuals are not normally distributed.

\section{Patients and public involvement}

In the early 2000s, the joint observation was introduced in our NICU by two professionals as part of the care of the parent-infant dyads. ${ }^{77}$ Due to positive feedback from the parents, the intervention was more routinely performed and systematised to the point that a randomised controlled trial was needed to examine its validity.

Although patients and caregivers' feedback was considered in designing and adapting the intervention, they were not directly involved in the design or recruitment of this study. However, results will be disseminated in written form to the participants and distributed to the public via social media and public events.

\section{Adverse events}

Expected and unexpected adverse events will be recorded during the study period. As the intervention does not involve medical or pharmaceutical treatment, the risk that an adverse event would occur is low. A child psychiatrist will be available for clinical assessment and follow-up if needed, particularly if significant psychological distress or psychiatric illness of the mother or her infant is detected during study participation.

\section{Data management}

All study data will be coded and entered by research staff (psychology assistant). The database will be regularly updated by the IT Service of the Lausanne University Hospital. Double data entry will be done for the primary outcomes. For the rest of the data, a random $5 \%$ will be double-checked. The principal investigator, the coinvestigators and the statistician will have access to the final trial data set. Individual participant data collected during the trial (after deidentification) on which publications from JOIN consortium are based will be available on reasonable request.

\section{Ethics and dissemination}

The local ethical committee approved the study protocol. Little to no risk is expected by participation of the mothers and their neonates in the trial. Signed informed consent will be obtained from all participating mothers. Participation in the study will not interfere with the typical care patients receive after childbirth and during NICU stay. Results from the study will be disseminated at national and international conferences, and in peer-reviewed journals. This randomised controlled trial is registered in clinicaltrials.gov (NCT02736136, Pre-results stage).

\section{Significance and outlook}

This study might result in an evidence-based early intervention aimed at reinforcing parental competences, in particular at increasing perceived parental self-efficacy. It would represent a brief, easily accessible and safe early intervention, which could be implemented in the routine care in the NICU, thus leading to significant changes in clinical practice. It will also help to characterise the relationships between perceived parental self-efficacy, maternal mental health, maternal perception of their relationship with their infant and their infant's temperament and maternal sensitivity.

Due to its interdisciplinary nature, this research is of interest for clinicians, educators and researchers in the field of paediatrics and development, psychology, child psychiatry and public health.

\section{Author affiliations}

${ }^{1}$ Woman-Mother-Child, Clinic of Neonatology, Centre Hospitalier Universitaire Vaudois, Lausanne, Switzerland

${ }^{2}$ Child and Adolescent Psychiatry, Centre Hospitalier Universitaire Vaudois, Lausanne, Switzerland

${ }^{3}$ Psychomotricity Institute, University of Applied Sciences and Arts Western Switzerland, Geneva, Switzerland

${ }^{4}$ Institute of Higher Education and Research in Healthcare, University of Lausanne, Lausanne, Switzerland

${ }^{5}$ Woman-Mother-Child, Clinic of Neonatology, Lausanne University Hospital, Lausanne, Switzerland

Acknowledgements We would like to thank Lyne Jaunin, Geneviève Métrailler Dizi and Manon Macherel for contributing to the writing of the ethics proposal. We acknowledge the contribution of Carole Muller-Nix and Margot Forcada-Guex to the development of the intervention. We are also grateful to Priska Udriot, Joanne Horisberger, Cassie Pernet and Vania Sandoz for help with data collection. Finally, we would like to acknowledge the Clinic of Neonatology, and Carole Richard, in particular for her support.

Collaborators Cindy Boche (Department of Woman-Mother-Child, Clinic of Neonatology, Lausanne University Hospital Center and University of Lausanne, Lausanne, Switzerland), Ayala Borghini (Department of Child and Adolescent Psychiatry, Lausanne University Hospital Center and University of Lausanne, Lausanne, Switzerland), Josée Despars (Department of Child and Adolescent Psychiatry, Lausanne University Hospital Center and University of Lausanne, Lausanne, Switzerland), Alice Manser Chenaux (Department of Woman-MotherChild, Clinic of Neonatology, Lausanne University Hospital Center and University of Lausanne, Lausanne, Switzerland), Noémie Faure (Department of WomanMother-Child, Clinic of Neonatology, Lausanne University Hospital Center and University of Lausanne, Lausanne, Switzerland), Valérie Goyer (Department of Woman-Mother-Child, Clinic of Neonatology, Lausanne University Hospital Center and University of Lausanne, Lausanne, Switzerland), Antje Horsch (Department of Woman-Mother-Child, Clinic of Neonatology, Lausanne University Hospital Center and University of Lausanne, Lausanne, Switzerland), Aurélie Le Berre (Department of Woman-Mother-Child, Clinic of Neonatology, Lausanne University Hospital Center and University of Lausanne, Lausanne, Switzerland), Maryline Monnier (Department of Woman-Mother-Child, Clinic of Neonatology, Lausanne University Hospital Center and University of Lausanne, Lausanne, Switzerland), Mathilde Morisod Harari (Department of Child and Adolescent Psychiatry, Lausanne University Hospital Center and University of Lausanne, Lausanne, Switzerland), Roxane Romon (Department of Woman-Mother-Child, Clinic of Neonatology, Lausanne University Hospital Center and University of Lausanne, Lausanne, Switzerland), Juliane Schneider (Department of Woman-Mother-Child, Clinic of Neonatology, Lausanne University Hospital Center and University of Lausanne, Lausanne, Switzerland), Catherine Sperandio (Department of Woman-Mother-Child, Clinic of Neonatology, Lausanne University Hospital Center and University of Lausanne, Lausanne, Switzerland), Chloé Tenthorey (Department of Woman-Mother-Child, Clinic of Neonatology, Lausanne University Hospital Center and University of Lausanne, Lausanne, Switzerland), Jean-François Tolsa (Department of Woman-MotherChild, Clinic of Neonatology, Lausanne University Hospital Center and University of Lausanne, Lausanne, Switzerland), and Aline Yersin (Department of Child and Adolescent Psychiatry, Lausanne University Hospital Center and University of Lausanne, Lausanne, Switzerland). 
Contributors All coauthors substantially contributed to the manuscript and approved the final version as submitted. AH and NF designed the study with input from all other members of the consortium. $\mathrm{AB}$ and $\mathrm{MMH}$ designed the intervention with input from members of the consortium. JS and AH drafted the manuscript and contributed equally to the present version. $\mathrm{AB}, \mathrm{MMH}, \mathrm{NF}, \mathrm{CT}, \mathrm{ALB}$ and J-FT significantly contributed to the establishment and refinement of study procedures and critically revised the manuscript.

Funding The authors have not declared a specific grant for this research from any funding agency in the public, commercial or not-for-profit sectors.

Competing interests None declared.

Patient consent for publication Not required.

Ethics approval Commission d'Ethique du Canton de Vaud, Switzerland, study number: 496/12

Provenance and peer review Not commissioned; externally peer reviewed.

Open access This is an open access article distributed in accordance with the Creative Commons Attribution Non Commercial (CC BY-NC 4.0) license, which permits others to distribute, remix, adapt, build upon this work non-commercially, and license their derivative works on different terms, provided the original work is properly cited, appropriate credit is given, any changes made indicated, and the use is non-commercial. See: http://creativecommons.org/licenses/by-nc/4.0/.

\section{REFERENCES}

1. Horbar JD, Carpenter JH, Badger GJ, et al. Mortality and neonatal morbidity among infants 501 to 1500 grams from 2000 to 2009. Pediatrics 2012;129:1019-26.

2. Back SA. Brain Injury in the preterm infant: new horizons for pathogenesis and prevention. Pediatr Neurol 2015;53:185-92.

3. Back SA, Miller SP. Brain injury in premature neonates: a primary cerebral dysmaturation disorder? Ann Neurol 2014;75:469-86.

4. Volpe JJ. Brain injury in premature infants: a complex amalgam of destructive and developmental disturbances. Lancet Neurol 2009;8:110-24.

5. Lasky RE, Williams AL. Noise and light exposures for extremely low birth weight newborns during their stay in the neonatal intensive care unit. Pediatrics 2009;123:540-6.

6. Sizun J, Pierrat V, Goubet N, et al. [Research, developmental care and NIDCAP: specific methodological issues]. Arch Pediatr 2007;14:S54-7.

7. Als H, Duffy FH, McAnulty GB. Effectiveness of individualized neurodevelopmental care in the newborn intensive care unit (NICU). Acta Paediatr 1996;85:21-30.

8. Westrup B, Stjernqvist K, Kleberg A, et al. Neonatal individualized care in practice: a Swedish experience. Semin Neonatol 2002;7:447-57.

9. Vandenberg KA. Individualized developmental care for high risk newborns in the NICU: a practice guideline. Early Hum Dev 2007;83:433-42.

10. Hane AA, Myers MM, Hofer MA, et al. Family nurture intervention improves the quality of maternal caregiving in the neonatal intensive care unit: evidence from a randomized controlled trial. J Dev Behav Pediatr 2015;36:188-96.

11. Symington A, Pinelli J. Developmental care for promoting development and preventing morbidity in preterm infants. Cochrane Database Syst Rev 2006;2:CD001814.

12. Burke S. Systematic review of developmental care interventions in the neonatal intensive care unit since 2006. J Child Health Care 2018;22:269-86.

13. Ohlsson A, Jacobs SE. NIDCAP: a systematic review and meta-analyses of randomized controlled trials. Pediatrics 2013;131:e881-93.

14. Montirosso R, Del Prete A, Bellù R, et al. Level of NICU quality of developmental care and neurobehavioral performance in very preterm infants. Pediatrics 2012;129:e1129-37.

15. Westrup B, Kleberg A, von Eichwald K, et al. A randomized, controlled trial to evaluate the effects of the newborn individualized developmental care and assessment program in a Swedish setting. Pediatrics 2000;105:66-72.

16. Nordhov SM, Rønning JA, Dahl LB, et al. Early intervention improves cognitive outcomes for preterm infants: randomized controlled trial. Pediatrics 2010;126:e1088-94.

17. Ortenstrand A, Westrup B, Broström EB, et al. The stockholm neonatal family centered care study: effects on length of stay and infant morbidity. Pediatrics 2010;125:e278-85.
18. Welch MG, Firestein MR, Austin J, et al. Family nurture intervention in the neonatal intensive care unit improves social-relatedness, attention, and neurodevelopment of preterm infants at 18 months in a randomized controlled trial. J Child Psychol Psychiatry 2015;56:1202-11.

19. Welch MG, Halperin MS, Austin J, et al. Depression and anxiety symptoms of mothers of preterm infants are decreased at 4 months corrected age with Family Nurture Intervention in the NICU. Arch Womens Ment Health 2016;19:51-61.

20. Hynan MT, Hall SL. Psychosocial program standards for NICU parents. J Perinatol 2015;35:S1-4.

21. Craig JW, Glick C, Phillips R, et al. Recommendations for involving the family in developmental care of the NICU baby. J Perinatol 2015;35:S5-8.

22. Purdy IB, Craig JW, Zeanah P. NICU discharge planning and beyond: recommendations for parent psychosocial support. $J$ Perinatol 2015;35:S24-8.

23. Jotzo M, Poets CF. Helping parents cope with the trauma of premature birth: an evaluation of a trauma-preventive psychological intervention. Pediatrics 2005:115:915-9.

24. Holditch-Davis D, Bartlett TR, Blickman AL, et al. Posttraumatic stress symptoms in mothers of premature infants. J Obstet Gynecol Neonatal Nurs 2003;32:161-71.

25. Roque ATF, Lasiuk GC, Radünz V, et al. Scoping review of the mental health of parents of infants in the NICU. J Obstet Gynecol Neonatal Nurs 2017;46:576-87.

26. Loo KK, Espinosa M, Tyler R, et al. Using knowledge to cope with stress in the NICU: how parents integrate learning to read the physiologic and behavioral cues of the infant. Neonatal Netw 2003;22:31-7.

27. Lau R, Morse CA. Stress experiences of parents with premature infants in a special care nursery. Stress and Health 2003;19:69-78.

28. Rautava P, Lehtonen L, Helenius $\mathrm{H}$, et al. Effect of newborn hospitalization on family and child behavior: a 12-year follow-up study. Pediatrics 2003;111:277-83.

29. Feeley N, Zelkowitz P, Cormier C, et al. Posttraumatic stress among mothers of very low birthweight infants at 6 months after discharge from the neonatal intensive care unit. Appl Nurs Res $2011 ; 24: 114-7$

30. Kersting A, Dorsch $M$, Wesselmann U, et al. Maternal posttraumatic stress response after the birth of a very low-birth-weight infant. $J$ Psychosom Res 2004;57:473-6.

31. Pierrehumbert B, Nicole A, Muller-Nix C, et al. Parental posttraumatic reactions after premature birth: implications for sleeping and eating problems in the infant. Arch Dis Child Fetal Neonatal Ed 2003;88:400F-4

32. Vanderbilt D, Bushley T, Young R, et al. Acute posttraumatic stress symptoms among urban mothers with newborns in the neonatal intensive care unit: a preliminary study. J Dev Behav Pediatr 2009;30:50-6.

33. DeMier RL, Hynan MT, Harris HB, et al. Perinatal stressors as predictors of symptoms of posttraumatic stress in mothers of infants at high risk. J Perinatol 1996;16:276-80.

34. Horsch A, Tolsa JF, Gilbert L, et al. Improving maternal mental health following preterm birth using an expressive writing intervention: a randomized controlled trial. Child Psychiatry Hum Dev 2016;47:780-91.

35. Feeley N, Hayton B, Gold I, et al. A comparative prospective cohort study of women following childbirth: mothers of low birthweight infants at risk for elevated PTSD symptoms. J Psychosom Res 2017:101:24-30.

36. Carter JD, Mulder RT, Bartram AF, et al. Infants in a neonatal intensive care unit: parental response. Arch Dis Child Fetal Neonatal Ed 2005;90:F109-13.

37. Aagaard H, Hall EO. Mothers' experiences of having a preterm infant in the neonatal care unit: a meta-synthesis. J Pediatr Nurs 2008;23:e26-36.

38. Preyde M, Ardal F. Effectiveness of a parent "buddy" program for mothers of very preterm infants in a neonatal intensive care unit. CMAJ 2003;168:969-73.

39. Feldman R, Eidelman Al. Maternal postpartum behavior and the emergence of infant-mother and infant-father synchrony in preterm and full-term infants: the role of neonatal vagal tone. Dev Psychobiol 2007;49:290-302.

40. Forcada-Guex M, Pierrehumbert B, Borghini A, et al. Early dyadic patterns of mother-infant interactions and outcomes of prematurity at 18 months. Pediatrics 2006;118:e107-14.

41. Woodward LJ, Bora S, Clark CA, et al. Very preterm birth: maternal experiences of the neonatal intensive care environment. J Perinatol 2014;34:555-61. 
42. Ionio C, Lista G, Mascheroni E, et al. Premature birth: complexities and difficulties in building the mother-child relationship. J Reprod Infant Psychol 2017;35:509-23.

43. Forcada-Guex M, Borghini A, Pierrehumbert B, et al. Prematurity, maternal posttraumatic stress and consequences on the motherinfant relationship. Early Hum Dev 2011;87:21-6.

44. Muller-Nix C, Forcada-Guex M. Perinatal assessment of infant, parents, and parent-infant relationship: prematurity as an example. Child Adolesc Psychiatr Clin N Am 2009;18:545-57.

45. Bilgin A, Wolke D. Maternal sensitivity in parenting preterm children: a meta-analysis. Pediatrics 2015;136:e177-93.

46. Montigny F, Lacharite C. Perceived parental efficacy: concept analysis. J Adv Nurs 2005;49:387-96.

47. Hess CR, Teti DM, Hussey-Gardner B. Self-efficacy and parenting of high-risk infants: the moderating role of parent knowledge of infant development. J Appl Dev Psychol 2004;25:423-37.

48. Bandura A. Self-efficacy: the exercise of control. New York: W.H: Freeman, 1997

49. Coleman PK, Karraker KH. Self-efficacy and parenting quality: findings and future applications. Developmental Review 1998;18:47-85.

50. Barnes CR, Adamson-Macedo EN. Perceived Maternal Parenting Self-Efficacy (PMP S-E) tool: development and validation with mothers of hospitalized preterm neonates. J Adv Nurs 2007;60:550-60.

51. Bandura A. Toward a psychology of human agency. Perspect Psychol Sci 2006;1:164-80.

52. Teti DM, Gelfand DM. Behavioral competence among mothers of infants in the first year: the mediational role of maternal self-efficacy. Child Dev 1991;62:918-29.

53. Leahy-Warren P, McCarthy G. Maternal parental self-efficacy in the postpartum period. Midwifery 2011;27:802-10.

54. Kohlhoff J, Barnett B. Parenting self-efficacy: links with maternal depression, infant behaviour and adult attachment. Early Hum Dev 2013;89:249-56.

55. Leahy-Warren P, McCarthy G, Corcoran P. First-time mothers: social support, maternal parental self-efficacy and postnatal depression. $J$ Clin Nurs 2012;21:388-97.

56. Benedetto L, Ingrassia M. Parental Self-efficacy in Promoting Children Care and Parenting Quality. In: Benedetto L, Ingrassia M, Parenting - empirical advances and intervention resources: INTECH, 2018.

57. Pennell C, Whittingham K, Boyd R, et al. Prematurity and parental self-efficacy: the preterm parenting \& self-efficacy checklist. Infant Behav Dev 2012;35:678-88.

58. Wells-Parker E, Miller DI, Topping JS. Development of control-ofoutcome scales and self-efficacy scales for women in four life roles. $J$ Pers Assess 1990;54:564-75.

59. Salonen $\mathrm{AH}$, Kaunonen M, Astedt-Kurki $\mathrm{P}$, et al. Parenting selfefficacy after childbirth. J Adv Nurs 2009;65:2324-36.

60. Haslam DM, Pakenham KI, Smith A. Social support and postpartum depressive symptomatology: the mediating role of maternal selfefficacy. Infant Ment Health J 2006;27:276-91.

61. Shea EM. Maternal self-esteem as affected by infant health infant behavior and family support. 1984.

62. Cutrona CE, Troutman BR. Social support, infant temperament, and parenting self-efficacy: a mediational model of postpartum depression. Child Dev 1986;57:1507-18.

63. Porter CL, Hsu HC. First-time mothers' perceptions of efficacy during the transition to motherhood: links to infant temperament. $J$ Fam Psychol 2003;17:54-64.

64. Campos JJ, Barrett KC, Lamb ME, et al. Handbook of child psychology. : Socioemotional development, 1983:2: 783-915.

65. Goldberg S, DiVitto B. Handbook of parenting Volume 1 children and parenting. 328: Parenting children born preterm, 1995

66. Harrison MJ, Magill-Evans J. Mother and father interactions over the first year with term and preterm infants. Res Nurs Health 1996;19:451-9.

67. Cambonie G, Muller JB, Ehlinger V, et al. Mother-infant interaction assessment at discharge and at 6 months in a French cohort of infants born very preterm: The OLIMPE study. PLoS One 2017:12:e0188942.

68. Seashore MJ, Leifer AD, Barnett CR, et al. The effects of denial of early mother-infant interaction on maternal self-confidence. J Pers Soc Psychol 1973;26:369-78.

69. Gennaro S. Postpartal anxiety and depression in mothers of term and preterm infants. Nurs Res 1988;37:82???85-5.

70. de Haan AD, Prinzie P, Deković M. Mothers' and fathers' personality and parenting: the mediating role of sense of competence. Dev Psychol 2009;45:1695-707.
71. Brecht C, Shaw RJ, Horwitz SM, et al. Effectiveness of therapeutic behavioral interventions for parents of low birth weight premature infants: a review. Infant Ment Health J 2012;33:651-65.

72. Meijssen DE, Wolf MJ, Koldewijn K, et al. Parenting stress in mothers after very preterm birth and the effect of the infant behavioural assessment and intervention program. Child Care Health Dev 2011;37:195-202.

73. Mendelson T, Cluxton-Keller F, Vullo GC, et al. NICU-based interventions to reduce maternal depressive and anxiety symptoms: a meta-analysis. Pediatrics 2017;139:e20161870.

74. Benzies KM, Magill-Evans JE, Hayden KA, et al. Key components of early intervention programs for preterm infants and their parents: a systematic review and meta-analysis. BMC Pregnancy Childbirth 2013;13:S10.

75. Ohgi S, Fukuda M, Akiyama T, et al. Effect of an early intervention programme on low birthweight infants with cerebral injuries. $J$ Paediatr Child Health 2004;40:689-95.

76. Teti DM, Black MM, Viscardi R, et al. Intervention With African American Premature Infants: Four-Month Results of an Early Intervention Program. J Early Interv 2009;31:146-66.

77. Borghini A, Forcada-Guex M. L'observation du bébé prématuré: un travail conjoint parents-spécialistes. Psychoscope 2004;5:20-2.

78. Brazelton TB, Nugent JK. Neonatal behavioral assessment scale: Cambridge University Press, 1995

79. Als $\mathrm{H}$. A synactive model of neonatal behavioral organization: framework for the assessment of neurobehavioral development in the premature infant and for support of infants and parents in the neonatal intensive care environment. Phys Occup Ther Pediatr 1986;6:3-53.

80. Bullinger A, Goubet N. Le bébé prématuré, acteur de son développement.. Enfance 1999;52:27-32.

81. McDonough S. Interaction guidance. Treating parent-infant relationship problems: Strategies for intervention, 2004:79-96.

82. Rusconi-Serpa S, Sancho Rossignol A, McDonough SC. Video feedback in parent-infant treatments. Child Adolesc Psychiatr Clin N Am 2009;18:735-51.

83. Kennedy H, Ball K, Barlow J. How does video interaction guidance contribute to infant and parental mental health and well-being? Clin Child Psychol Psychiatry 2017;22:500-17.

84. Hoffenkamp HN, Tooten A, Hall RA, et al. Effectiveness of hospitalbased video interaction guidance on parental interactive behavior, bonding, and stress after preterm birth: a randomized controlled trial. J Consult Clin Psychol 2015;83:416-29.

85. Tooten A, Hoffenkamp HN, Hall RA, et al. The effectiveness of video interaction guidance in parents of premature infants: a multicenter randomised controlled trial. BMC Pediatr 2012;12:76.

86. Borghini A, Habersaat S, Forcada-Guex M, et al. Effects of an early intervention on maternal post-traumatic stress symptoms and the quality of mother-infant interaction: the case of preterm birth. Infant Behav Dev 2014;37:624-31.

87. Martinet M, Borradori Tolsa C, Rossi Jelidi M, et al. Development and assessment of a sensory-motor scale for the neonate: a clinical tool at the bedside. Arch Pediatr 2013;20:137-45.

88. Wild D, Grove A, Martin M, et al. Principles of good practice for the translation and cultural adaptation Process for Patient-Reported Outcomes (PRO) Measures: report of the ISPOR Task force for translation and cultural adaptation. Value Health 2005;8:94-104

89. Foa EB, Cashman L, Jaycox L, et al. The validation of a self-report measure of posttraumatic stress disorder: the posttraumatic diagnostic scale. Psychol Assess 1997;9:445-51.

90. Hearn M, Ceschi G, Brillon P, et al. A French adaptation of the posttraumatic diagnostic scale. Can J Behav Sci 2012;44:16-28.

91. Miles MS, Funk SG, Carlson J. Parental stressor scale: neonatal intensive care unit. Nurs Res 1993;42:148-52.

92. Abidin RR, Index PS. Parenting Stress Index (PSI). Odessa, FL: Psychological Assessment Resources, 1995.

93. Singer LT, Salvator A, Guo S, et al. Maternal psychological distress and parenting stress after the birth of a very low-birth-weight infant. JAMA 1999;281:799-805.

94. Abidin RR. Parenting stress index: professional manual. 3rd ed. Odessa, FL: Psychological Assessment Resources, Inc, 2012.

95. Zigmond AS, Snaith RP. The hospital anxiety and depression scale. Acta Psychiatr Scand 1983;67:361-70.

96. Bocéréan C, Dupret E. A validation study of the Hospital Anxiety and Depression Scale (HADS) in a large sample of French employees. BMC Psychiatry 2014;14:354

97. Cox JL, Holden JM, Sagovsky R. Detection of postnatal depression Development of the 10-item edinburgh postnatal depression scale. Br J Psychiatry 1987;150:782-6.

98. Guedeney N, Fermanian J. Validation study of the French version of the Edinburgh Postnatal Depression Scale (EPDS): new 
results about use and psychometric properties. Eur Psychiatry 1998;13:83-9.

99. Taylor A, Atkins R, Kumar R, et al. A new Mother-to-Infant Bonding Scale: links with early maternal mood. Arch Womens Ment Health 2005;8:45-51.

100. van Bussel JC, Spitz B, Demyttenaere K. Three self-report questionnaires of the early mother-to-infant bond: reliability and validity of the dutch version of the MPAS, PBQ and MIBS. Arch Womens Ment Health 2010;13:373-84.

101. Horsch A, Jacobs I, Gilbert L, et al. Impact of perinatal asphyxia on parental mental health and bonding with the infant: a questionnaire survey of Swiss parents. BMJ Paediatr Open 2017;1:e000059.

102. Putnam SP, Helbig AL, Gartstein MA, et al. Development and assessment of short and very short forms of the infant behavior questionnaire-revised. J Pers Assess 2014:96:445-58.

103. Moser A, Stuck AE, Silliman RA, et al. The eight-item modified medical outcomes study social support survey: psychometric evaluation showed excellent performance. J Clin Epidemiol 2012;65:1107-16.

104. Sherbourne CD, Stewart AL. The MOS social support survey. Soc Sci Med 1991;32:705-14.
105. Largo RH, Pfister D, Molinari L, et al. Significance of prenatal, perinatal and postnatal factors in the development of AGA preterm infants at five to seven years. Dev Med Child Neurol 1989;31:440-56.

106. Parry G, Tucker J, Tarnow-Mordi W, et al. CRIB II: an update of the clinical risk index for babies score. Lancet 2003;361:1789-91.

107. Biringen Z, Robinson JL, Emde RN. Appendix A: the emotional availability scales (2nd ed.; an abridged infancy/Early Childhood version). Attach Hum Dev 2000;2:251-5.

108. Biringen Z, Robinson J. Emotional availability in motherchild interactions: a reconceptualization for research. $A m \mathrm{~J}$ Orthopsychiatry 1991;61:258-71.

109. Crittenden PM. The care index. infants and toddlers. Family Relations Institute: Miami, FL, 2001.

110. Bayley N. Bayley scales of infant and toddler development: bayleyIII: harcourt assessment, psych. Corporation San Antonio, TX, 2006.

111. Faul F, Erdfelder E, Lang AG, et al. G*Power 3: a flexible statistical power analysis program for the social, behavioral, and biomedical sciences. Behav Res Methods 2007;39:175-91.

112. Rothman KJ. No adjustments are needed for multiple comparisons. Epidemiology 1990;1:43-6. 